\title{
RADICALISMOS À BRASILEIRA
}

\author{
WALTER GARCIA põe em confronto os "radicalismos" nas \\ canções de João Gilberto, Chico Buarque e dos Racionais MC's
}

\section{A ALEGRIA MELANCÓLICA DE JOÃO GILBERTO*}

Em novembro de 1992, Lorenzo Mammì publicou "João Gilberto e o projeto utópico da bossa nova”. No ensaio, percebia-se um contínuo ir-e-vir entre a forma artística (que se queria descrever) e o processo histórico (condensado na e potencializado pela forma artística). Citando livremente uma passagem de Antonio Candido, diga-se que o movimento buscava a análise do elemento social "como fator da própria construção artística, estudado no nível explicativo e não ilustrativo" [1]. E citando mais livremente uma passagem de outro crítico literário, Roberto Schwarz, diga-se que o ensaio identificava, na obra de João Gilberto, a capacidade de "formalizar, explorar e levar ao limite revelador as virtualidades de uma condição histórico-prática”[2].

Desde então, o ensaio de Lorenzo Mammì se tornou referência para vários textos. Infelizmente, porém, muitosdeles se limitaram à citação de meia-frase: "a bossa nova é promessa de felicidade". A frase inteira é "Se o jazz é vontade de potência, a bossa nova é promessa de felicidade", e nela se sintetizauma argumentação desenvolvida ao longo de todo o ensaio.

Mammì parte de um lugar-comum: "Bossa nova é classe média, carioca". Contudoeste lugar-comum começa a readquirirvalor interpretativologo na sequência: a bossa nova "sugere a ideia de uma vida sofisticada sem ser aristocrática, de um conforto que não se identifica com o poder. Nisto está sua novidade e sua força. Mas aí está também seu ponto fraco"[3].

A fim de justificar, então, o pensamento dialético - isto é, onde reside a novidade

\footnotetext{
* Antes de ser apresentado na série Atualidade da crítica, este estudo da obra de João Gilberto foi exposto no III Encontro de Estudos da Palavra Cantada, em agosto de 2011, e resulta de um projeto de pesquisa realizado com auxílio da FAPESP. Agradeço a Cláudia Neiva de Matos os comentários que auxiliaram na revisão bibliográfica e na formulação da hipótese.

1. CANDIDO, Antonio. 2000. “Crítica e sociologia”. In: Literatura e sociedade. 8a ed. São Paulo: T. A. Queiroz/ Publifolha, p. 8.

2. SCHWARZ, Roberto. 1987. "A carroça, o bonde e o poeta modernista”. In: Que horas são? São Paulo: Companhia das Letras. p. 23.

3. MAMMİ, Lorenzo. 1992. "João Gilberto e o projeto utópico da bossa nova”. Novos estudos Cebrap, n³4. São Paulo, novembro. p. 63.
} 
e a força também residiria o ponto fraco -, Mammì estabelece um paralelo entre o surgimento da bossa nova, no Brasil da década de 1950, e "a passagem do dixieland para a era do swing", nos Estados Unidos de "meados da década de 20" e durante a década de 1930. Nos EUA, "a organização interna da big band" acabaria por figuraro negativo do trabalho alienado na fábrica, uma vez que "o produto final (...) não é o resultado da mera divisão de tarefas, e sim da adição de atos criadores". No Brasil, um quadro diverso corresponderia à geração da bossa nova:

\footnotetext{
"A intimidade tão exibida nos shows de bossa nova, o excesso de apelidos carinhosos (Tonzinho, Joãozinho, Poetinha), tão contrastantes com a boemia cruel de Noel Rosa, esta necessidade contínua de confirmações afetivas- tudo isso talvez sinalize um mal-estar de quem ficou suspenso entre uma antiga sociabilidade, que se perdeu, e uma definição nova, mais racional e transparente, que não conseguiu se realizar. Ou talvez seja a forma com que a geração criadora do novo estilo resiste em se reconhecer produtiva, apresentando o seumais rigoroso trabalho como um lazer, como o resultado ocasional de uma conversa de fim de noite".
}

Assim estabelecido, o paralelo parececoncluir pela vantagem do swing sobre a bossa nova. Todavia a conclusão é outra e aponta para a necessidade de uma maior investigação: haveria, na bossa nova, algo que as outras tradições musicais não possuem e que exerce um fascínio sobre elas.

Em síntese, trata-se da "auto-suficiência do canto", cuja intuição lírica "exige que se acredite numa espécie de espontaneidade" [4]. Mas é preciso levar em conta que à "auto-suficiência do canto" se articulam outros materiais:

1.no trabalho de Tom Jobim, "o predomínio absoluto da linha melódica" sobre outros parâmetros musicais - harmonia, arranjo, orquestração[5];

2.no trabalho de João Gilberto, o "horizonte ideal" de seu canto: "um ponto em que seja suficiente falar com perfeição para que a linha melódica brote espontaneamente da palavra, uma vez encontrada a inflexão e a cor exata de cada sílaba" [6].

3.ainda no trabalho de João Gilberto, opulso musical que, ao relativizar a "oposição forte/fraco", configuraria "uma pulsação doméstica, o correr indefinido das horas em que ficamos em casa”[7].

\footnotetext{
4. Ibidem. p. 64 e 65 .

5. Ibidem. p. 65

6. Ibidem. p. 68 .

7. Ibidem. p. 69 .
} 
A articulação desses elementos formaisdotaria a obra de João Gilberto, em especial, de "uma carga utópica" referida desde o título do ensaio:

\footnotetext{
"uma sensação de temporalidade suspensa que não é ócio, mas uma atividade que se produz naturalmente, sem sofrimento ou esforço, como por emanação. Nela, a dimensão afetiva das palavras supera a funcional em exatidão e em capacidade propositiva" [8]
}

Daí a "promessa de felicidade", utopia da qual diverge a "vontade de potência" do jazz. No jazz, organiza-se a experiência de uma "vida particular [que] é sempre uma forma de treino para a vida pública" e também se projeta "uma autoconsciência" que inverte "a divisão taylorista do trabalho"[9]. Já na bossa nova, organiza-se o que se poderia denominar utopia cordial. Remeto-me à sociabilidade descrita por Sérgio Buarque de Holanda,ao célebre tipo do homem cordial, aquele que desconhece "qualquer forma de convívio que não seja ditada por uma ética de fundo emotivo". A matéria histórica em que se assenta a cordialidade é a supremacia dos domínios rurais sobre os centros urbanos, o que significa dizer que a ética cordial - a supremacia dasrelaçõesafetivas, das vontades particulares,da opinião tradicional sobre os princípios neutros e abstratos, sobre as normas antiparticularistas de organização social - dá prova da "persistência dos velhos padrões coloniais"[10]. Mammì não cita Raízes do Brasil mas, se não estou enganado em minha leitura, "João Gilberto e o projeto utópico da bossa nova" aponta para a cristalização,na forma daquele "novo samba", da cordialidade no quadro da ideologia de uma parcela do Brasil tradicional; parcela que talvez tenha sido hegemônica, durante a segunda metade da década de 1950, quando aspirou a se tornar moderna. Nesse sentido, a bossa nova de João Gilberto sugere a ideia de uma vida sofisticada que é, sim, de certo modo aristocrática.

Embora eu concorde que a canção de João Gilberto seja portadora de uma dimensão utópica. E embora também concorde que o lirismo do sujeito que canta emblematicamente "chega de saudade" se vincula, em chave histórica, ao otimismo das classes(média e alta) que acreditaram na harmonia entre as"conquistas materiais do capitalismo" e "a persistência dos traços de caráter que nos singularizavam como povo"[11] entre parênteses, não custa reparar

\footnotetext{
8. $\quad$ Ibidem. p. 70 .

9. Ibidem. p. 69 e 64 .

10. HOLANDA, Sérgio Buarque de. 2001. Raízes do Brasil. 26 ed., 11 a reimpressão. São Paulo: Companhia das Letras. p. 146, 148 e 161.

11. MELLO, João Manuel Cardoso de \& NOVAIS, Fernando A. 2004. "Capitalismo tardio e sociabilidade moderna”. In: SCHWARCZ, Lilia Moritz (org.). História da vida privada no Brasil: contrastes da intimidade
} 
quetalutopiacorrige ou ignora umaparte fundamental da cordialidade: a ética cordial "não abrange, [...] apenas e obrigatoriamente, sentimentos positivos", segundo já havia observado Sérgio Buarque[12].

Embora eu concorde com tudo isto, creio que há um elemento essencial, na estrutura da obra de João Gilberto, que ainda carece de análise e de interpretação. Um elemento que inclusive permanece ofuscado pela meia-frase "a bossa nova é promessa de felicidade"quando esta é repetida quase como um slogan.

Refiro-me à melancolia.[13] Generalizando, as disposições ensolaradas- alegria, esperança, otimismo - só se sobrepõem à sombra melancólica quando o jogo sonoro da voz e do violão de João Gilberto predomina sobre o conteúdo lírico. Citar como exemplo desse predomínio as gravações de "O pato" (Jaime Silva/ Neuza Teixeira) não conta muito, pois se trata de uma narrativa ingênua, sendo mais ou menos óbvio que a graça reside não apenasna humanização dos bichos, mas principalmente na humanização do ouvinte que se deixa encantar pelo ritmo e pelo colorido dos sons. Assim, para ficarcom melhorexemplo, escute-se a gravaçãodo samba "De conversa em conversa" (Lúcio Alves/ Haroldo Barbosa), realizada por João em 1970.

Porém não é sempre que o jogo sonoro predomina, fazendo com que o sentido se incline ao ensolarado. Quando o conteúdo lírico sobressai, via de regra a voz de João Gilberto mantém em equilíbrio a alegria e a melancolia, a esperança sem efusão e alamentação sem lamúria. Os sentimentos, logicamente entre si

contemporânea. $3^{\text {a }}$ reimpressão. São Paulo: Companhia das Letras. pp. 559-658. *João Manuel Cardoso de Mello e Fernando A. Novais não se referem expressamente à bossa nova, mas ao que "alguns imaginavam" na década de 1950 .

12. HOLANDA, Sérgio Buarque de. 2001. Raízes do Brasil 26ª ed., 11ª reimpressão. São Paulo: Companhia da Letras.

13. Lorenzo Mammì não tratou da melancolia em "João Gilberto e o projeto utópico da bossa nova”. Trataria do sentimento no prefácio que escreveu ao Cancioneiro Jobim:

"Na Bossa Nova, a volta à primeira parte da canção é o retorno a um lugar que não é mais o mesmo, porque o tempo passou à nossa revelia. O que se acumulou na viagem não é energia, mas experiência. O tempo triufa sobre nós, nessas músicas, mas se abandonar a ele é prazerosamente sábio, ainda que um pouco triste.

(...) A Bossa Nova é imitação do tempo da conversa: uma sequência de momentos insubstituíveis, porque cada um se carrega de um significado afetivo que não pode se repetir" (MAMMİ, Lorenzo. 2000. "Prefácio". In: JOBIM, Paulo et alii(coord.). Cancioneiro Jobim: obras escolhidas. Rio de Janeiro: Jobim Music/ Casa da Palavra.).

Todavia, se não estou equivocado, a passagem acusa uma alteração importante no método de análise: não se observa o processo histórico quando se aborda a sensação do irremediável do tempo enquanto matéria com que a bossa nova de Tom Jobim se produz. Já em outro texto, no qual não trata da, mas apenas cita a melancolia, Lorenzo Mammì novamente estará buscando vínculos entre os recursos da canção e o andamento social. É quando o crítico fará a ligação entre a "postura de conciliação" da utopia da bossa nova e, dentre outros traços, "o registro expressivo [que] permanecia nos tons intermediários: melancolia, ironia gentil, alegria contida. Como os objetos futuristas da ficção científica da época, a bossa nova não tinha ângulos nem arestas, era lisa e arredondada" (MAMMİ, Lorenzo. 2008. Prefácio. In: JOBIM, Ana Lontra et alii (coord.) Cancioneiro Chico Buarque, vol. 2. Rio de Janeiro: Jobim Music. p. 13-24). 14). Com minhas reflexões, espero dar um passo adiante no esclarecimento do vínculo entre expressão melancólica, "alegria contida" e "postura de conciliação". 
contraditórios, aparecem na superfície como se não conflitassem. Talento artístico à parte, o que se pode afirmar é que o famoso canto baixinho possibilita a nuança dos sentimentos, auxiliado pela distância que o intérprete toma da matéria que expressa: é como se o sujeito expressasse, de modo natural e reservado, a observação atenta que faz de um estado d’alma; um estado d’alma por ele intensamente sentido e por ele depurado.

De modo quase didático, pode-se conferiro equilíbrio entre melancolia e esperança, que aqui tento explicar, na comparação de três gravações que se fizeram de "Outra vez", de Tom Jobim. A composição foi gravada por Dick Farney em 1954, por Elizete Cardoso em 1958, e por João Gilberto em 1960.

A síntese do que se ouve com Dick Farney é “Tudo agora é só tristeza/ Traz saudade de você", versos que fecham a segunda parte. Canta-seo fracasso amoroso repetido ou contínuo - o que nos leva a pensar em obsessão e em masoquismo, na "celebração do amor impossível e da fatalidade da solidão", marcas do sambacanção da zona sul carioca na primeira metade da década de 1950[14]. Com Elizete Cardoso, esse tema é sublimado. Não se exprime nem a solidão, nem a saudade. Caso permaneça desatento ao sentido intelectual das palavras, o ouvinte poderá achar que se trata simplesmente de um sambinha eufórico, sem atinar com o porquê do entusiasmo do sujeito da canção.

Já a síntese da gravação de João Gilberto é "Até você voltar", frase que ele canta na oitava de cima em relação às outras duas gravações.[15] Canta-se a expectativa do fim da solidão, o que não quer dizer que se cante a plenitude amorosa ou qualquer instânciapara além do bem e do mal. De forma direta, exprime-se a observação de um estado d’alma que inclui tanto a esperança quanto a saudade ea tristeza, num outro modo de entoar "o amor é a coisa mais triste/ quando se desfaz".

Talvez uma das razões para que a melancolia permaneça ofuscada na crítica de João Gilberto seja a insistência no vínculo entre oseu trabalho, a expressão "bossa nova" e a memória afetiva de um estilo de vida da classe média na zona sul carioca durante os chamados anos dourados. Não entrarei aqui na discussão do rótulo "bossa nova”.[16] Todavia penso que seja mais justo relacionar a obra de João Gilberto ao processo histórico desencadeado, de forma crucial, a partir da crise de

14. LENHARO, Alcyr. 1995. Cantores do rádio: A trajetória de Nora Ney \&Jorge Goulart e o meio artístico de seu tempo. Campinas: Editora da Unicamp. p. 109.

15. Dick Farney gravou “Outra vez” em Ré Maior. Elizete Cardoso, em Si Maior. João Gilberto, em Dó Maior. As diferenças de tonalidade não interferem na sensação causada pela frase "Até você voltar" na voz de João.

16. A discussão sobre os vários sentidos da expressão "bossa nova”, tanto ao início dos anos de 1960 como em tempos recentes, foi bem encaminhada por Edinha Diniz (2001). "A grande síntese”. Jornal do Brasil, caderno JG Especial 70 anos, 3 de junho. pp. 2-4. 
1929 e do movimento de 1930, dois marcos que assinalam "o fim da hegemonia agrário-exportadora e o início da predominância da estrutura produtiva de base urbano-industrial"[17].

Isto porque o seu repertório é feito de canções compostas, por uma feliz coincidência, a partir de 1929, ano da primeira gravação de "Linda flor", de Henrique Voggeler, com letra de Luiz Peixoto - João Gilberto gravou-a com Maria Bethânia em 1990. Junto do repertóriohá, pelo menos, dois fatosdaquele processo histórico diretamente implicados no trabalho de João Gilberto: a expansão das novas tecnologias de comunicação (rádio, disco e cinema); e a construção ideológica do samba como emblema da nação brasileira.À luz desse quadro, é de se comparar, p. ex., as gravações de "Aos pés da cruz" (Marino Pinto/ Zé da Zilda) com Orlando Silva, em 1942, e com João Gilberto, em 1959. Com Orlando Silva, o samba convida à dança, ainda que não tenha sido gravado para o carnaval. $\mathrm{O}$ andamento é mais acelerado, a densidade sonoraé maior. $\mathrm{O}$ canto é mais exaltado do que o de João Gilberto, exaltação afim com a tonalidade mais aguda, umaquinta acima da tonalidade de João.[18] O canto de João Gilberto não comunica a transfiguração da dor pela dança, permanecendo mais próximo do pensamento do que da celebração.

Escutem-seainda as gravações de "Aquarela do Brasil" (Ary Barroso) e de "Bahia com H” (Denis Brian) no disco Brasil, de 1981, com João Gilberto, Caetano Veloso e Gilberto Gil. A voz de Gilberto Gil parece mal se conter, como se a emissão represasse uma energia que precisaria soar com maior intensidade; tratase de uma voz pautada sobretudo pela alegria. A voz de Caetano Veloso radica na sensualidade. João Gilberto traz a sensação do tempo passado em equilíbrio com o tempo presente em que se situa o seu ponto de vista. É um canto melancólico, ainda que da melancolia tome certa distância ao permanecer "atento, sobretudo, ao desenho musical e silábico"[19].

Minha hipótese é que João Gilberto, desde 1958, trabalha com a matéria histórica da euforia da modernidade e também com a matéria histórica do tempo que foge, esta última, captada na observação da vida que se modificou tão velozmente no Brasil a partir de 1930. A "sensação de temporalidade suspensa", referida por Lorenzo Mammì e, com outras palavras, também por outros estudiosos (p. ex., David Treece fala em "animação suspensa"), essa suspensão no tempo produzida

17. OLIVEIRA, Francisco de. 2003. Crítica à razão dualista/ O ornitorrinco. São Paulo: Boitempo Editorial. p. 35.

18. Nas gravações consideradas, Orlando Silva cantou "Aos pés da cruz" em Si Maior e João Gilberto, em Mi Maior.

19. SCHWARZ, Roberto. 1992. "As casas de Cristina Barbosa”. In: O pai de família e outros estudos. $2^{\text {a }}$ ed. Rio de Janeiro: Paz e Terra. p. 111-113. 
pela voz e pelo violão de João Gilberto expressaria a junção de expectativa do futuro e de busca de abrigo contra o tempo.

Em suma, se a hipótese não está equivocada, a obra de João projeta harmonizar a dor causada pelo "lento cataclismo" da cordialidade[20] com a alegria pela modernidade que se goza e que se almeja, a qual (paradoxalmente) causa a ruína da cordialidade. Dizendo de outro modo, seu samba projeta transformar em enlace o choque de Brasil tradicional com Brasil moderno. Daí a esperança sem efusão. Daí, também, a lamentação sem lamúria.

Tentarei levar um pouco mais adiante a análise. Desde a década de 1960, muito se escreveu sobre arevolução musical trazida por João Gilberto. O canto que fica próximo da fala mas que também é percussivo;a relação entre avoz e os acordes do violão; o trabalho de síntese e de estilização do samba;os processos de composição de letra e melodia (levando-se em conta, sobretudo, obras que se inspiraram no seu estilo ou que desdobraram a sua estética); o pensamento sobre a canção popular brasileiraem diálogo com a canção popular de outros países e com diversas formas da arte moderna - tudo isso foi avaliado como revolucionário. Não discordo dessa valoração de João Gilberto, mas gostaria de propor um outro enfoque.

Tomando por base a distinção entre "radical" e "revolucionário" estudada por Antonio Candido, a utopia cordial de João não configura uma estética propriamente revolucionária. Seu lugar é ao lado de outras obras artísticas que deram expressão a pensamentos radicais. Trabalhos que formam "contrapeso ao movimento conservador que sempre predominou" no Brasil. E "que não se integram em sistemas" [21], muito embora a descontinuidade de ideias e de atitudes não impeça que se identifique, em épocas distintas, uma constante "de rebeldia nascida e alimentada nos setores intelectualizados da pequena burguesia brasileira (profissionais liberais, estudantes, escritores, artistas, políticos, etc.)"[22]

Curioso é que no Brasil também se identifique, segundo Candido, o radicalismo "como desvio ocasional da mentalidade das classes dominantes, inclusive as

\footnotetext{
20. Entre aspas, cito para meus propósitos expressão de Sérgio Buarque, quando assinala que "ainda testemunhamos presentemente, e por certo continuaremos a testemunhar durante largo tempo, as ressonâncias últimas do lento cataclismo" de "iberismo e agrarismo", termos que se confundem "no Brasil, e não só no Brasil" (Holanda, 2001: 172).

21. CANDIDO, Antonio. 1995. "Radicalismos”. In: Vários escritos. $3^{a}$ ed., revista e ampliada. São Paulo: Duas Cidades. p. 265-266.

22. BUARQUE, Chico e PONTES, Paulo. 1976. “Apresentação". In: Gota d’água. 3a ed. Rio de Janeiro: Civilização Brasileira. p.xi-xx.
} 
oligarquias tradicionais" [23]. Considerar a radicalidade de João Gilberto ajuda a esclarecer por que a sua arte e o seu comportamento de artista parecem um tanto deslocados nas casas de espetáculo em que ele se apresenta. E, no entanto, haveria local mais adequado para o seu trabalho?

\section{A AMEAÇA QUE NÃO VEM DO INIMIGO}

Passo agora à análise de Chico Buarque, expondo uma crítica ainda em processo. O ponto de contato entre esta parte e a anterior é a noção de "radicalismo" estudada porAntonio Candido. Na soma das duas análises, pretendo acenar com um esquema de interpretação da canção popular brasileira, esquema, por ora, apenas esboçado.

Salvo engano, quem primeiro chamou a atenção para a radicalidade da canção de Chico Buarque foi Adélia Bezerra de Meneses, em entrevista para a revista Cult publicada em 2003. Na entrevista, Meneses se referia à clara intenção do compositor de, ao retratar tipos sociais marginalizados, "os desvalidos e oprimidos”, dar "voz àqueles que em geral não têm voz”[24]: “(...) isso é um extraordinário traço de radicalidade que ele teve de quem herdar”[25]. Após a afirmação, a estudiosa sumariou a crítica de Raízes do Brasil feita porAntonio Candido no seu texto "Radicalismos".

Será interessante retomar aqui uma declaração do próprio Chico Buarque, em entrevista à revista Ocasde 24 de julho de 2004, quando foi perguntado sobre os efeitos que a violência na cidade do Rio de Janeiro teria lhe causado:

\footnotetext{
"A mim, pessoalmente, muito pouco. Na semana passada, roubaram a bicicleta da minha filha, por exemplo, ali na Lagoa. Todas as minhas meninas já foram assaltadas mais de uma vez, mas eu nunca fui. Nunca andei de relógio, anel, corrente, até para evitar isso, para não ter muito o que levarem. Então, desses pequenos crimes ando mais ou menos salvo. Mas isso não quer dizer nada. Essa confusão não me afeta fisicamente, mas de resto afeta tudo. É ruim estar nessa loucura. Não vivo com paranoias, não tenho essa preocupação. Já passei por climas parecidos, mas que eram mais fáceis de lidar. Por exemplo, no tempo da repressão, sendo realmente ameaçado de ser morto, sofrer acidentes, eu convivia com isso. Não era paranoia de repente chegar uma caixa na minha casa e eu ter que atirar longe para ver
}

\footnotetext{
23. CANDIDO, op. cit., p. 269.

24. MENESES, Adélia Bezerra de. 2000. Desenho mágico: poesia e política em Chico Buarque. 2a ed. São Paulo: Ateliê Editorial. p. 125.

25. MENESES, Adélia Bezerra de. 2003. "Lirismo e resistência”, entrevista a Manuel da Costa Pinto. Cult, ano VI, no 69. São Paulo, Editora 17. p. 59.
} 
se explodia. Mas o que acontece hoje é que você vive com esse clima, e o que te ameaça não vem do inimigo. Esses caras que estão fazendo isso, eu provavelmente dou razão a eles (grifo meu). Se o cara quiser entrar aqui em casa e levar essa porra toda, me dar porrada, eu vou ficar muito puto, não vou gostar de apanhar, mas no fim das contas vou pensar que se eu estivesse no lugar dele faria a mesma coisa. Às vezes as pessoas jogam pedras do mirante aqui na minha piscina, e eu penso que, se eu estivesse lá em cima, também jogaria, entende? Estou lá, vendo isso tudo aqui embaixo, estou sem um puto, eu não vou virar evangélico, não vou ler a Bíblia, talvez tente trabalhar e não consiga nada e, aí ainda mais, eu vou querer aquela bicicleta daquela garota que está passeando na Lagoa”. [26]

Sabe-se que uma coisa são as ideias manifestadas pelo autor, a sua biografia, os traços de sua personalidade. Outra coisa é a obra artística estudada na sua própria forma.E nunca é simples analisar as relações entre a especificidade da obra e aquilo que o autor planejava. De todo modo, a declaração faz lembrar "Pivete" (em parceria com Francis Hime), "O meu guri”, "Ode aos ratos (em parceria com Edu Lobo)/Embolada”, nas quais o compositor não condena seus personagens, o que não quer dizer que as canções façam apologia a roubo e furto. $\mathrm{O}$ mesmo se observa em "Brejo da Cruz": o compositor/narrador não condena a criançada que vê "se alimentar de luz", o que não quer dizer que a canção faça apologia ao consumo de drogas, ao estado de abandono de menores e à miséria.

Entretanto pode-se generalizar um outro comentário do próprio Chico Buarque, em entrevista para a revista Caros Amigos, em 1998. Chico falava sobre "Gota d'água" e "Bem-querer", compostas por ele para a personagem Joana, da peça Gota d’água, escrita junto com Paulo Pontes. Joana é uma "Medeia do subúrbio". Mas o que ela canta "não são canções monstruosas. A melodia, de certa forma, adocica o que poderia haver de literatura em uma letra de música" [27]. Generalizando, então, o comentário: a forma como os versos são cantados adocicam a monstruosidade das situações retratadas por Chico Buarque em "Pivete", "O meu guri", "Ode aos ratos/Embolada" ou "Brejo da Cruz", estabelecendo-se desse modo o limite da intenção progressista, isto é, da radicalidade da sua obra.

Junte-se a tal generalização a análise de uma apresentação de "Brejo da Cruz" na

26. BUARQUE, Chico. 2004. “Já estou pegando o violão”. Ocas, 24/07/2004. Versão eletrônica, http://www. chicobuarque.com.br/texto/index.html. Acesso em 6 jan. 2005.

27. BUARQUE, Chico. 1998. “Chico, o craque de sempre”, entrevista a Ana Miranda, Regina Echeverria, Plínio Marcos, José Arbex Jr., Carlos Tranjan, Marco Frenette, Johnny, Walter Firmo e Sérgio de Souza em Caros Amigos, ano 2, no 20. São Paulo, Casa Amarela, dezembro. p. 23. 
tevê. Refiro-me ao especial Chico ou o país da delicadeza perdida[28], levado ao ar pela televisão francesa em 1990. Entre parênteses, não custa notar que o título do especial se tornou uma espécie de slogan, como se deu com"a bossa nova é promessa de felicidade". Naquela apresentação de "Brejo da cruz"feita para a tevê:

1.as imagens dos meninos pobres são plasticamente muito belas;

2.o cantor no palco, embora demonstre ou deixe escapar algum constrangimento, sorri e dança satisfeito ao solo do sax;

3.o balanço do acompanhamento instrumental atrai muito a atenção do espectador.

Na junção dos três elementos, o que há de crítica social na letra de "Brejo da cruz" sai, para dizer o mínimo, bastante prejudicado.

Encerrarei com um breve comentário a respeito de "Sinhá", parceria de Chico Buarque com João Bosco, última faixa do disco Chico, lançado em 2011. Creio que o samba pode ser melhor entendido se comparado a "Negro drama" (Edy Rock/ Mano Brown), rap do grupo Racionais MC’s lançado em 2002. A comparação não é fortuita, como não seria fortuito cotejar "Querido diário", primeira faixa do disco Chico, a "Diário de um detento" (Mano Brown/ Jocenir), lançado pelo Racionais em 1997. Já "Subúrbio", composição de 2006 de Chico Buarque, citava "Águas de março" e fazia eco a uma rima que se escuta em "Diário de um detento":

\author{
"Perdido em ti \\ Eu ando em roda \\ É pau, é pedra \\ É fim de linha \\ É lenha, é fogo, é foda" (“Subúrbio"); \\ “"Esses papos me incomoda, se eu tô na rua, é foda...” \\ 'É, o mundo roda, ele pode vir pra cá”" (“Diário de um detento”).[29]
}

\footnotetext{
28. BUARQUE, Chico. 2003. Chico ou o país da delicadeza perdida. [p1990]. Direção Walter Salles Jr. e Nelson Motta. BMG, 82876538929.

29. Estudei o ponto de vista de "Subúrbio" quando da revisão de minha tese de doutorado, Melancolias, mercadorias: Dorival Caymmi, Chico Buarque, o pregão de rua e a canção popular-comercial no Brasil, tese defendida na área de Literatura Brasileira da USP: “Águas de março', de Tom Jobim, canta 'É pau, é pedra/ É o fim do caminho'; 'É a lenha, é o dia/ É o fim da picada'. Talvez a palavra 'linha' tenha sido sugerida a Chico Buarque, para 'Subúrbio', pela semelhança sonora com 'lenha' ou pela presença das linhas da Central do Brasil; ainda assim, não há motivos para se descartar a referência à chamada linha evolutiva, sobretudo porque o que se canta ali é o término, o desmoronamento do projeto de civilização que deu substância à MPB. Já o campo lexical de 'foda' também havia sido pensado por Tom para a letra esboçada de um hino ao Rio de Janeiro, não concluído: 'Rio dos bandidos/ Rio dos feridos/ Rio dos fodidos'; mas a palavra 'fodidos' está riscada no rascunho (SUKMAN, Hugo. 2004. "Pois, palavras e bolinhas". Globo, Segundo Caderno, 3 de outubro. p.1.)”. Sobre a coincidência,que pode não ter sido intencional, entre "Subúrio" e "Diário de um detento", cf. GARCIA, Walter. 2007. "Diário de um detento’: uma interpretação”. In: NESTROVSKI, Arthur (org.). Lendo música. São Paulo: Publifolha, p. 208. “Diário de um detento’: uma interpretação”. In: NESTROVSKI, Arthur (org.). Lendo música. São Paulo: Publifolha, p. 208. Vale dizer que essas ideiasforam apresentadas nos Seminários das Quartas (organizados por
} 
De resto, "Pivete", "O meu guri" e "Ode aos ratos/Embolada" condensam matéria histórica semelhante à condensadaem "Tô ouvindo alguém me chamar", "12 de outubro" e "Eu sou 157", composições de Mano Brown, o que indica que tampouco a comparação entre os dois grupos seria forçada. Novo parêntese: no meu entendimento,a comparação surpreenderia quem toma, em princípio, as composições de Chico Buarque como aquelas que revelam de modo mais amplo e mais aprofundado o processo histórico.

Em "Negro drama", Edy Rock canta sua trajetória pessoal, que "Não é conto nem fábula, lenda ou mito": "O dinheiro tira um homem da miséria/ Mas não pode arrancar de dentro dele a favela". E Mano Brown, também cantando sua experiência, se dirige ao "senhor de engenho": "Eu sou problema de montão, de carnaval a carnaval/ Eu vim da selva, sou leão, sou demais pro seu quintal". Apresentado em show gravado para o DVD 1000 trutas 1000 tretas, o rap mobiliza de tal forma o público que é difícil não sentir, em potência, umaação coletivaque visa à subversão da herança escravista de desigualdade econômica e segregação social[30].

Já o samba "Sinhá", em andamento desacelerado, nos faz ouvir um "conto" construído com apoio da historiografia. Um conto que é terrível: um escravo é aleijado no tronco, é açoitado e tem os olhos furados. Mas o embalo da canção não adocicaria, aqui também, o relato mostruoso? E como avaliar o riso de Chico Buarque, quando glosa para seu público da internet a letra que compôs? Refirome ao documentário Dia voa, o qual cobriu e divulgou a gravação do disco Chico: "É o escravo contando, cantando a história dele (risos) e tomando porrada, e contando e contando e contando"[31].

Seja como for, na parte final do samba, o "cantor atormentado" se apresenta como "Herdeiro sarará/ [...] De um feroz senhor de engenho/ E das mandingas de um escravo/ Que no engenho enfeitiçou Sinhá”. De modo geral, notou também Chico Buarque em outro especial feito para a tevê, o rap "é uma negação desse formato de canção" com que ele sempre trabalhou[32]. Esquematicamente, trata-se de duas formas diferentes de canção popular, que nascem a partir de dois pontos de vista - de classe - diferentes.

Paulo Eduardo Arantes e Anderson Gonçalves) na FFLCH-USP em agosto de 2006. E também em aulas, uma das quais no Centro Universitário Maria Antonia em abril de 2007. Não foi sem surpresa que, antes de sair em livro a tese revisada, encontrei paráfrases da interpretação em artigo de quem me ouviu falar em público, sem a devida indicação da fonte. Deve haver algum elogio escondido nessa acumulação primitiva de idéias.

30. (RACIONAIS MC’s, 2006).

31. BUARQUE, Chico. 2011. Dia voa. www.chicobastidores.com.br. Acesso em 23 set. 2011.

32. BUARQUE, Chico. 2006. Romance. Direção Roberto de Oliveira. RWR/ EMI, 3584439. 
De um lado, "Negro drama" expressa o revide à violência atual recebida pela classe baixa, com ódio alimentado da imagem dos antepassados escravizados. De outro lado, "Sinhá" expressa a consciência de saber-se herdeiro tanto da crueldade desmedida quanto das artimanhas de quem só dispunha dos feitiços de sedução. Neste quadro, é evidente que a violência do senhor de engenho branco é superior e miserável. Mas o escravo negro não faz papel de inocente,[33] o que dificulta o maniqueísmo e alimenta de tormento a consciência - radical - desse cantor sarará de classe média.

WALTER GARCIA é professor da área temática de música do Instituto de Estudos Brasileiros e autor de, entre outros, Bim Bom: a contradição sem conflitos de João Gilberto (Paz e Terra).

33. Devo a observação a comentário de Ton Lopes. Agradeço a ele e a Marília Calderón, David Forell, Marcelo Segreto, Vinícius Gueraldo e Yuri Prado a oportunidade de discutir "Sinhá”. 